\title{
Castleman's disease and neutropenic enterocolitis presenting as Crohn's disease
}

\author{
Kelly W Burak MD, Ronald J Bridges MD FRCPC, Walter B Blahey MD FRCPC
}

KW Burak, RJ Bridges, WB Blahey. Castleman's disease and neutropenic enterocolitis presenting as Crohn's disease. Can J Gastroenterol 1998;12(4):270-272. A rare case of Castleman's disease presenting as Crohn's disease is described. This 21-yearold male with chronic neutropenia for one year presented with recurrent right lower quadrant pain of two years' duration. Small bowel follow-through suggested Crohn's of the terminal ileum. Colonoscopy confirmed ulcerations in the terminal ileum and cecum, with biopsies showing necrosis and inflammation. Treatment was initiated with prednisone, 5-aminosalicylate and granulocyte colony-stimulating factor for neutropenia. Symptoms recurred one year later, and repeat colonoscopy showed a focal cecal ulceration. Two years after presentation a resection was planned. Laparotomy revealed a normal ileocecal region and a large retroperitoneal mass of lymphadenopathy. Biopsies confirmed reactive hyperplasia, consistent with the plasma cell variant of Castleman's disease. Chemotherapy has resulted in improvement of symptoms and decrease in mass size, but cecal ulceration persisted. This case illustrates a variant presentation of Castleman's disease with neutropenia and manifestations in the gastrointestinal tract.

Key Words: Castleman's disease, Cecal ulcer, Crohn's disease, Neutropenia, Neutropenic enterocolitis, Typhlitis

\section{Maladie de Castleman et entérocolique neutropénique ayant l'apparence d'une maladie de Crohn}

\begin{abstract}
RÉSUMÉ : On décrit ici un cas rare de maladie de Castleman se présentant comme une maladie de Crohn. Ce jeune homme de 21 ans souffrant de neutropénie chronique depuis un an se présentait pour douleurs récurrentes au quadrant inférieur droit depuis deux ans. L'examen du grêle donnait à penser à une maladie de Crohn au niveau de l'iléon terminal. La colonoscopie a confirmé la présence d'ulcérations à cet endroit et cæcum et les biopsies faisaient état de nécrose et d'inflammation. Un traitement été instauré avec prednisone, 5-aminosalicylate et facteur stimulant les colonies de granulocytes pour la neutropénie. Les symptômes sont revenus un an plus tard et la reprise de la colonoscopie a révélé une ulcération cæcale localisée. Deux ans après la présentation initiale, une résection a été prévue. À la laparotomie, on a noté une région iléo-cæcale normale et une importante masse rétropéritonéale de lymphadénopathie. Les biopsies ont confirmé une hyperplasie réactive concordant avec la variante à plasmocytes de la maladie de Castleman. La chimiothérapie a amélioré les symptômes et réduit la taille de la masse, mais les ulcérations cæcales ont persisté. Ce cas illustre un tableau différent de la maladie de Castleman avec neutropénie et manifestations gastro-intestinales.
\end{abstract}

$\mathrm{C}$ astleman's disease, also known as giant lymph node hyperplasia, is a rare disorder of the lymph nodes. It may follow a benign indolent course presenting with asymptomatic lymphadenopathy. However, a multicentric variety has been described that can have an aggressive clinical course and severe systemic manifestations (1). Rarely, patients present with extranodal involvement. This case of multicentric Castleman's disease was complicated by chronic neutropenia and typhlitis of the cecum and terminal ileum that mimicked Crohn's disease.

This paper was a winning entry in the 'Consultations in Gastroenterology' Case Study Competition that was initiated and funded with the generous sponsorship of Astra Canada and is endorsed by the Canadian Association of Gastroenterology

Department of Medicine, University of Calgary, Calgary, Alberta

Correspondence: Dr Kelly Burak, Foothills Hospital, 1403-29th Street NW, Calgary, Alberta T2N 2T9. Telephone 403-670-1110, fax 403-270-7479, e-mail burakk@cadvision.com 


\section{CASE PRESENTATION}

A 21-year-old male presented in January 1995 for assessment of a two-year history of right lower quadrant pain. The pain, initially intermittent, had been persistent for the preceding three months. It was not severe and did not wake him from sleep. It was unrelated to food intake or defecation. There was no history of diarrhea or blood in the stools. There was no nausea, vomiting, fever, chills or night sweats. His weight was constant. He had perianal discomfort for six weeks, but no evidence of fistulous discharge. He previously had had oral ulcers and low back discomfort, but there was no history of arthritis, eye complaints, jaundice, cholelithiasis or nephrolithiasis.

Past medical history was significant for chronic neutropenia diagnosed in 1993. Bone marrow biopsy was normal, and he had polyclonal gammopathy and a positive Coombs' test. His neutropenia was thought to be immune-mediated and had responded to prednisone in the past. He was on no prescription or over-the-counter medications and had no allergies. He was a nonsmoker and drank little alcohol. There was no family history of inflammatory bowel disease, autoimmune disorders, malignancy or neutropenia.

Examination revealed no jaundice, clubbing or palpable lymphadenopathy. Chest and cardiovascular examinations were normal. His abdomen was soft with mild tenderness in the right lower quadrant. There was no palpable mass or hepatosplenomegaly. Rectal examination revealed a small anterior tag, with no evidence of a fissure or fistula, and normal rectal mucosa. Laboratory investigations revealed neutropenia and anemia (white blood cell count $1.8 \times 10^{9}$, neutrophils $0.3 \times 10^{9}$, hemoglobin $104 \mathrm{~g} / \mathrm{L}$, mean corpuscular volume $65.0 \mathrm{fL}$ ).

A small bowel follow-through showed thickened mucosal folds of the cecum and terminal ileum. Colonoscopy revealed normal colonic mucosa except for an edematous ileocecal valve with a well-circumscribed ulcer (Figure 1A). The terminal ileum was edematous with well-defined ulcers. Biopsies revealed necrosis and inflammation consistent with origin from an ulcer. No granulomas were identified.

The patient was started on prednisone with resolution of abdominal symptoms. 5-aminosalicylate was substituted for prednisone, but was discontinued by the patient. Granulocyte colony-stimulating factor was used intermittently to increase the neutrophil count. In January 1996, the patient experienced a recurrence of right lower quadrant pain. Repeat colonoscopy in November 1996 showed focal superficial ulceration at the ileocecal valve, with biopsies again showing nonspecific inflammation. He settled on prednisone, but once the dose was tapered his symptoms recurred and surgical resection was planned. A laparotomy done in March 1997 revealed a normal ileocecal region, and no resection was performed. The spleen was enlarged and there was a large left-sided peri-aortic mass consistent with lymphadenopathy. Biopsies showed reactive hyperplasia with intact germinal centres. Between follicles was an extensive plasma cell infiltrate that was polyclonal in origin. This was felt to be the plasma cell variant of Castleman's disease.

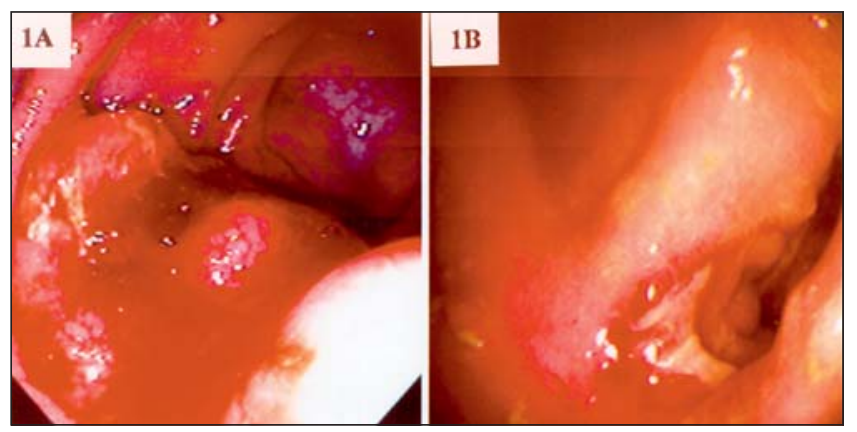

Figure 1) A Colonoscopy done in January 1995 showing edematous and friable ileocecal valve; B Repeat colonoscopy performed in November 1997 showing isolated cecal ulcer

The patient was again treated with prednisone; however, by June 1997 his right lower quadrant pain intensified. Computed tomography (CT) scan showed focal adenopathy in the left para-aortic region and mild splenomegaly. Chemotherapy was started and following each of six courses of cyclophosphamide, vincristine and prednisone there was temporary improvement in the abdominal pain. Repeat CT scan in December 1997 showed a decrease in size of lymphadenopathy, but a cecal ulcer persisted on colonoscopy (Figure 1B). In April 1998, the patient underwent surgical resection of the cecum for persistent symptoms. Further chemotherapy is planned.

\section{DISCUSSION}

Castleman's disease was first described in 1956 in patients with localized mediastinal lymphadenopathy (2). It typically presents with intrathoracic lymphadenopathy but can affect any lymph node group, and extranodal disease has been described (1). There is reactive lymph node enlargement with characteristic histological features that can be classified into two distinct subtypes (1). The hyaline-vascular variant accounts for $90 \%$ of cases and is usually localized with an indolent course. The plasma cell variant is more likely to be extrathoracic, multicentric and clinically aggressive. The pathology, although characteristic, can be seen in other conditions including connective tissue disease, drug reactions and immunosuppression. Therefore, the diagnosis of Castleman's disease requires the appropriate clinical setting. Localized disease is seen in younger patients, can be treated with surgical excision and has an excellent prognosis (100\% survival at five years) (1). Multicentric disease frequently has an aggressive course, including progression to lymphoma (3). Patients in this group are often older, with systemic symptoms and hepatosplenomegaly. They often have associated autoimmune cytopenias, hypoalbuminemia, elevated erythrocyte sedimentation rate or hypergammaglobulinemia $(3,4)$. Treatment usually involves chemotherapy, and prognosis is poor, with a median survival of 26 months (3). The etiology is unclear but may involve increased levels of interleukin- 6 and possibly human herpesvirus $8(3,5)$.

Our patient demonstrated features of multicentric Castleman's disease including splenomegaly, polyclonal gammo- 
pathy, anemia and chronic neutropenia. His presentation of right lower quadrant pain with persistent cecal ulceration was initially thought to be due to Crohn's disease. However, biopsies of the area were nonspecific, and most likely are due to a form of typhlitis secondary to his chronic neutropenia. Typhlitis usually presents with fever, nausea, vomiting and generalized or right lower quadrant pain (6). It tends to involve the cecum and terminal ileum, and its pathogenesis is not clearly defined. Neutropenic enterocolitis is usually seen following chemotherapy for hematological malignancies, but cases have been reported following chemotherapy for other malignancies, after drug reactions, in patients with organ transplants and in benign cyclic neutropenia $(6,7)$.

Reported gastrointestinal manifestations of Castleman's disease in the literature are infrequent. They include two cases of gastric ulceration and a case of colonic blood loss from an adjacent mass of Castleman's disease (8). Masses mimicking gastric and pancreatic neoplasms have been described (9-11). Associated intestinal lymphangiectasia has been reported (12). A case involving resection of localized retroperitoneal Castleman's disease, resulting in resolution of anemia and hypergammaglobulinemia, suggested that surgery may have benefit in our patient (13). However, neutropenic enterocolitis in association with Castleman's disease has not previously been described and is an interesting complication of this patient's associated chronic neutropenia.

\section{REFERENCES}

1. Shahidi H, Myers JL, Kvale PA. Castleman's disease. Mayo Clin Proc 1995;70:969-77.

2. Castleman B, Iverson L, Menedez VP. Localized mediastinal lymph-node hyperplasia resembling thymoma. Cancer 1956;9:822-30.

3. Peterson BA, Frizzera G. Multicentric Castleman's disease. Semin Oncol 1993;20:636-47.

4. Carrington PA, Anderson H, Harris M, Walsh SE, Houghton JB, Morgenstern G. Autoimmune cytopenias in Castleman's disease. Am J Clin Pathol 1990;94:101-4.

5. Corbellino M, Poirel L, Aubin JT, et al. The role of human herpesvirus 8 and Epstein-Barr virus in the pathogenesis of giant lymph node hyperplasia (Castleman's disease). Clin Infect Dis 1996;22:1120-1.

6. Wade DS, Nava HR, Douglas HO. Neutropenic enterocolitis, clinical diagnosis and treatment. Cancer 1992;69:17-23.

7. Abbasoglu O, Cakmakci M. Neutropenic enterocolitis in patients without leukemia. Surgery 1993;113:113-6.

8. Wengrower D, Libson E, Okon E, Goldin E. Gastrointestinal manifestations in Castleman's disease. Am J Gastroenterol 1990;85:1179-81.

9. Yebra M, Vargas JA, Menedez VP, et al. Gastric Castleman's disease with a lupus-like circulating anticoagulant. Am J Gastroenterol 1989;84:566-70.

10. LeVan TA, Clifford S, Staren ED. Castleman's tumour masquerading as a pancreatic neoplasm. Surgery 1989;106:884-7.

11. Schulman H, Sickel J, Klienman MS, Adams JT. Gastric "pseudolymphoma" with restricted light chain expression in a patient with obscure gastrointestinal blood loss. Dig Dis Sci 1991;36:1495-9.

12. Moss SF, Thomas DM, Mulnier C, McGill IG, Hodgson HJF. Intestinal lymphangiectasia associated with angiofollicular lymph node hyperplasia (Castleman's disease). Gut 1992;33:135-7.

13. Seco JL, Velasco F, Manuel JS, Serrano SR, Tomas L, Velasco A. Retroperitoneal Castleman's disease. Surgery 1992;112:850-5. 


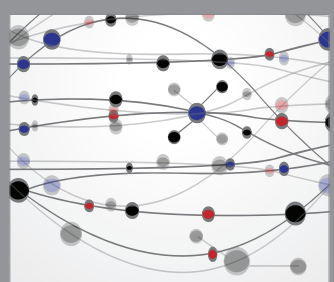

The Scientific World Journal
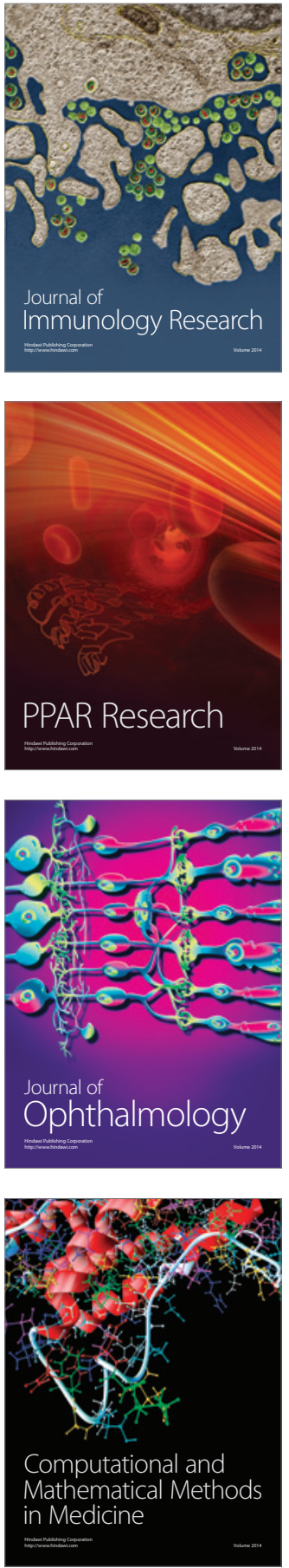

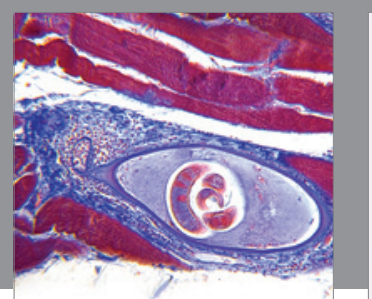

Gastroenterology Research and Practice

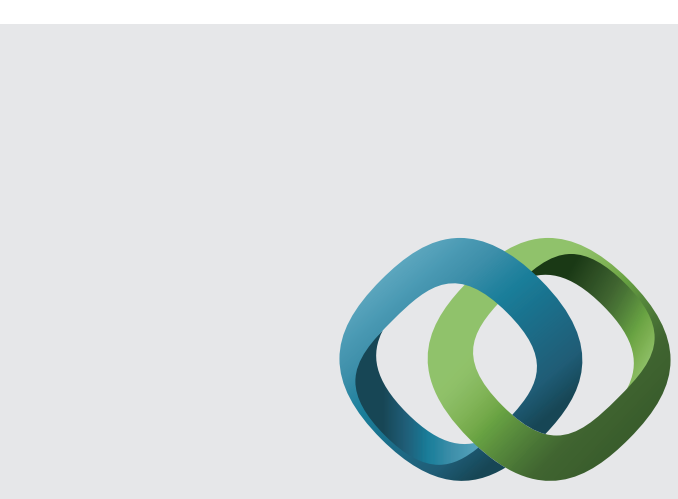

\section{Hindawi}

Submit your manuscripts at

http://www.hindawi.com
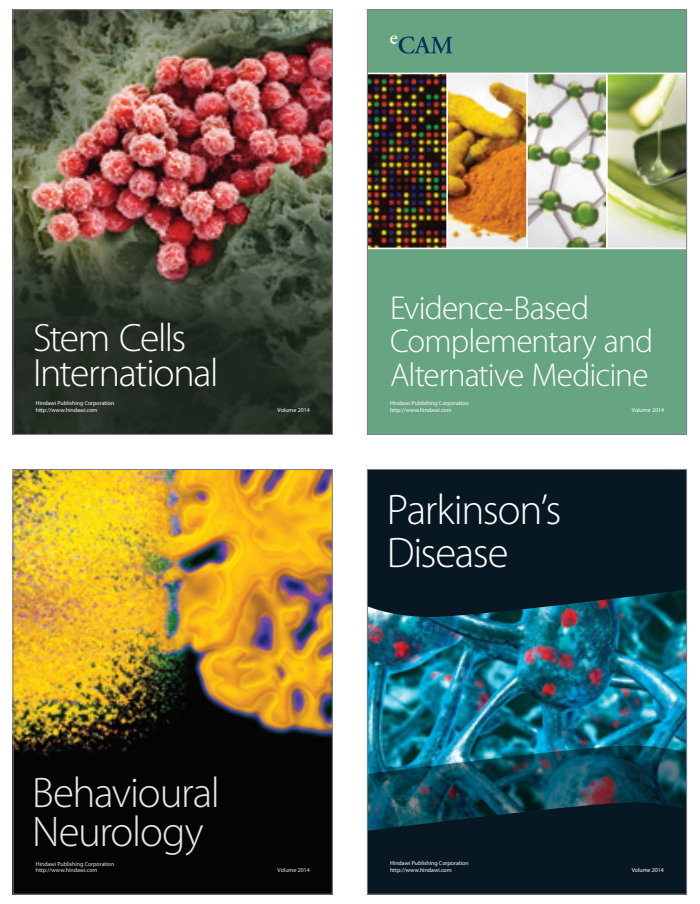
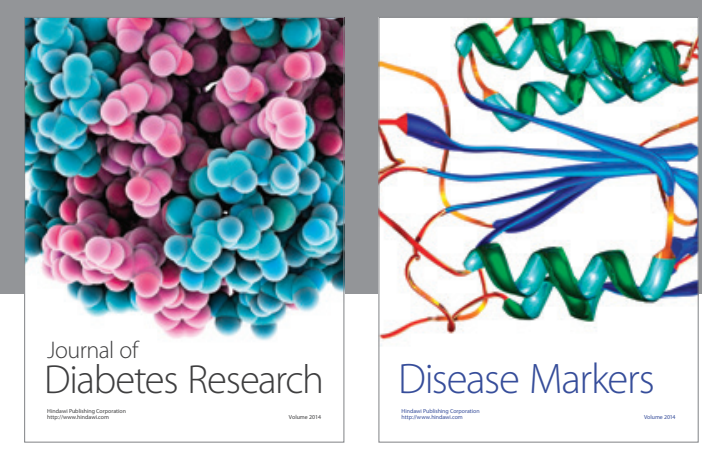

Disease Markers
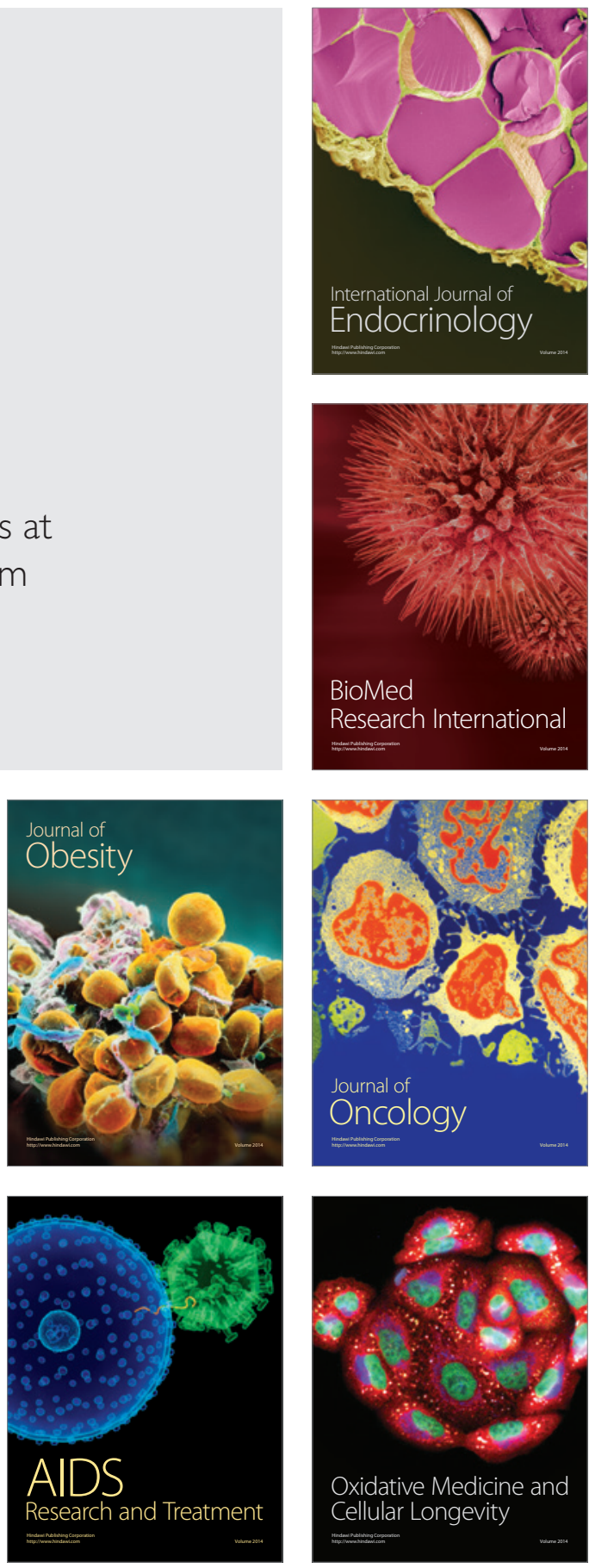